\title{
Divertículo gástrico simulando lesión suprarrenal
}

\section{Gastric Diverticulum Simulating Adrenal Lesion}

\author{
Cristian Miguel Daher ${ }^{1}$ Cristina Anahí Namuncurá ${ }^{1}$ \\ ${ }^{1}$ Clínica Pasteur, Neuquén, Neuquén, Argentina \\ Rev Argent Radiol 2019;83:173-175.
}

\section{Estimados Editores:}

Los divertículos gástricos (DG) son raros y generalmente se detectan de manera incidental durante las pruebas de diagnóstico de rutina del tracto gastrointestinal superior. Pueden simular otras patologías, como las masas tumorales necróticas o quísticas.

Presentamos el caso de un paciente de sexo masculino de 50 años de edad, con antecedentes de tabaquismo crónico, que consultó al servicio de Guardia por tos con expectoración sanguinolenta. Se le indicó la realización de tomografía computada (TC), con posterior diagnóstico de enfisema centrolobulillar bilateral, micronódulos pulmonares, adenopatías mediastinales y nódulo en proyección de la glándula suprarrenal izquierda ( - Fig. 1).

Se le realizó una resonancia magnética $(\mathrm{RM})$ con contraste endovenoso, en la que se visualizó, proyectada en la glándula

\author{
Carlos Kugler ${ }^{1}$
}

Address for correspondence Dr. Cristian Miguel Daher, Los Ceibos 1451, Cipolletti, Río Negro, Argentina (e-mail: cristianmdaher@gmail.com).

suprarrenal izquierda, una imagen sacular que presentaba comunicación con el estómago, de 2,3 $\times 2,8 \mathrm{~cm}$ de diámetro, con contenido líquido, compatible con DG ( - Fig.2). Se evaluó con mayor repleción gástrica, por RM y TC, confirmando dicho diagnóstico (-Fig. 3).

El DG es una afección rara que afecta a la pared gástrica. La prevalencia oscila entre el $0,04 \%$ en las radiografías del estudio de contraste, el $0,1-2,6 \%$ en las series de autopsias, $y$ el $0,01-0,11 \%$ en la endoscopia esófago-gastroduodenal. ${ }^{1-3}$

Pueden simular otras entidades, como masas tumorales quísticas y o necróticas.

Los métodos de imágenes son determinantes en el diagnóstico del DG.

Se da en personas con edades comprendidas entre los $20 \mathrm{y}$ los 60 años, sin predominio de sexo. ${ }^{3}$ Generalmente
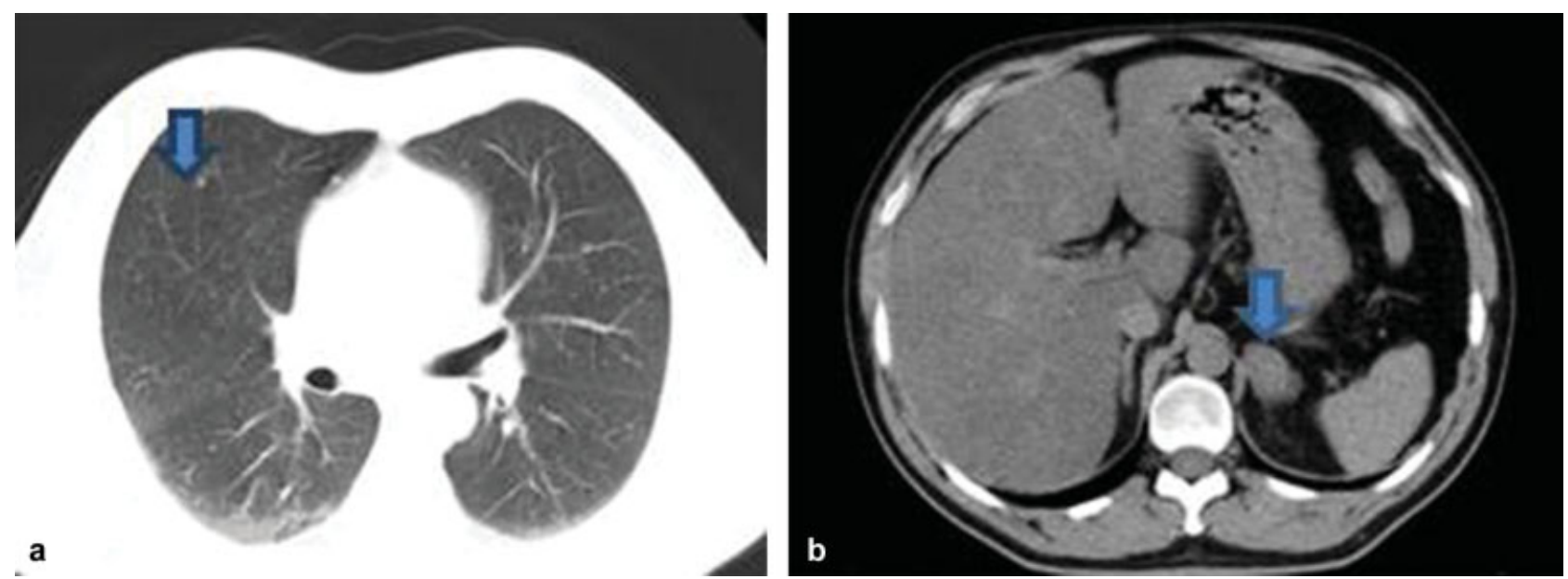

Fig. 1 TC de tórax sin contraste endovenoso (a) y de abdomen superior sin contraste oral ni endovenoso. (b) Micronódulo en pulmón derecho (flecha) y macronódulo en proyección de la glándula suprarrenal izquierda (flecha).

received

April 12, 2018

accepted

May 14, 2019
DOI https://doi.org/

$10.1055 / \mathrm{s}-0039-1692437$

ISSN 1852-9992.
Copyright @ $\odot$ 2019, Sociedad Argentina de Radiología. Publicado por Thieme Revinter Publicações Ltda., Rio de Janeiro, Brazil. Todos los derechos reservados.
License terms

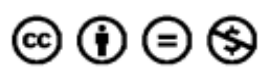



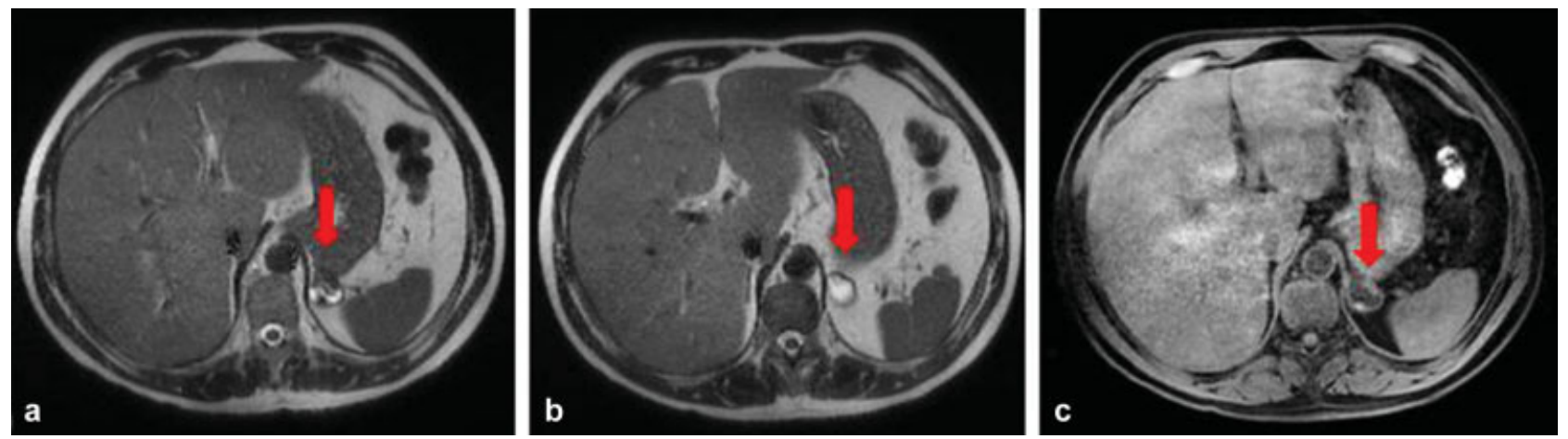

Fig. 2 RM de abdomen sin contraste oral ni endovenoso, en el plano axial en secuencias ponderadas en T2 (a y b) y LAVA (c), donde se visualiza imagen hiperintensa en secuencias ponderadas en T2, hipointensa en LAVA, líquida, de pared delgada, comunicada con el estómago (flechas rojas).
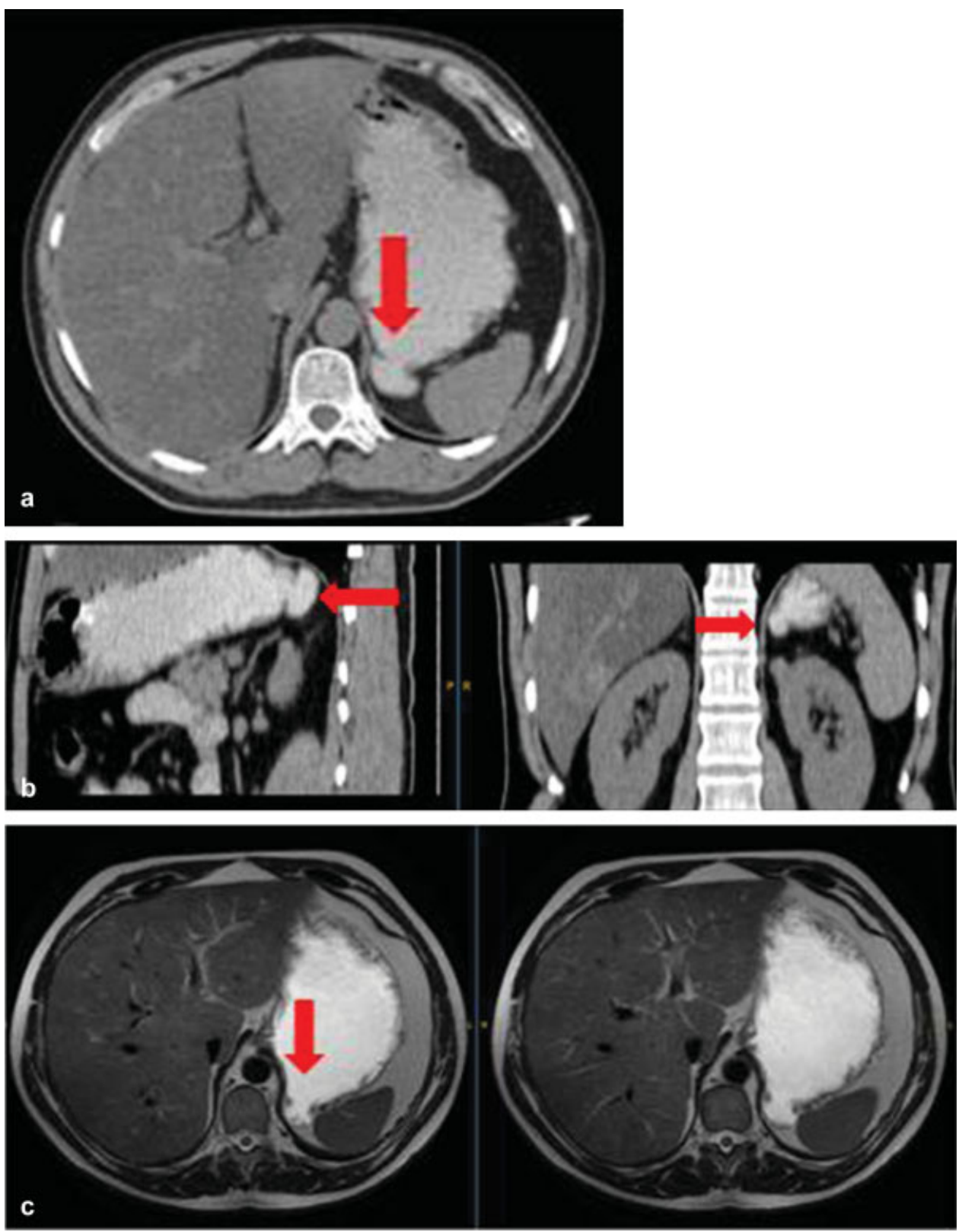

Fig. 3 TC de abdomen con contraste oral en los planos axial (a), reconstrucción sagital y coronal (b) y RM de abdomen con contraste oral, en el plano axial (c), con mayor repleción gástrica. Distensión del divertículo, comunicado con el estómago (flechas rojas). 
asintomáticos, pueden presentar síntomas como dispepsia, vómitos, dolor abdominal y complicaciones como ulceración, perforación, hemorragia o torsión. 4,5

Se describen dos tipos de divertículos: congénitos y adquiridos. Los congénitos comprenden entre el $70 \%$ y el $75 \%{ }^{3}$ Se presentan en la región del cardias del estómago. ${ }^{4}$ Generalmente son solitarios y presentan todas las capas del estómago. Se forman por una debilidad subyacente en la pared gástrica, resultante de la división de las fibras musculares longitudinales lisas en el cardias. ${ }^{5}$

Los adquiridos son pseudo-divertículos, no contienen capas musculares y se dividen en dos clases: de conducción o de tracción. Los de conducción aparecen debido a un aumento en la presión intraluminal (tos crónica, obesidad, embarazo). Los de tracción son causados por adherencias adyacentes al estómago, secundarias a una enfermedad concomitante, como pancreatitis, enfermedad ácido-péptica o derivación gástrica, y se localizan cerca de la región antral. ${ }^{6}$

La resección quirúrgica del divertículo está indicada cuando es grande y sintomático o cuando hay complicaciones. ${ }^{6}$

La seriada esófago-gástrica (SEG) o la endoscopía (operador dependiente) son métodos diagnósticos de certeza, aunque en divertículos de cuello estrecho pueden dar falsos negativos. ${ }^{3}$

La TC contribuye al diagnóstico, aunque pueden dar falsos positivos en variantes anatómicas, lobulación esplénica, estructuras vasculares esplénicas dilatadas o tortuosas, masa renal, suprarrenal o de la cola del páncreas, que pueden simular tumores suprarrenales.

Del gas que contiene las masas quísticas puede sugerir infección, tumor necrótico o una estructura que se comunica con el tracto gastrointestinal. El absceso y la neoplasia necrótica suelen tener una pared gruesa, a diferencia del divertículo, que tiene pared delgada. ${ }^{3}$

La RM, debido a su resolución de contraste y capacidad multiplanar, es de utilidad para el diagnóstico, en especial para descartar los diagnósticos diferenciales.

La apariencia típica de DG es una lesión quística de pared delgada con nivel aire-líquido y una conexión con el tracto gastrointestinal.
La visualización de su conexión del tracto gastrointestinal en la reconstrucción de imágenes, ya sea por TC o RM, es determinante en el diagnóstico. ${ }^{6}$

Es importante recordar la posibilidad de observar DG a nivel del fondo, que pueden simular una lesión de órgano adyacente, como en nuestro caso.

\section{Confidencialidad de los datos}

Los autores declaran que han seguido los protocolos de su centro de trabajo sobre la publicación de datos de pacientes y que todos los pacientes incluidos en el estudio han recibido información suficiente y han dado su consentimiento informado por escrito para participar en dicho estudio.

\section{Conflicto de Intereses}

Los autores declaran no tener ningún conflicto de intereses, con excepción del Dr. Cristian Miguel Daher, que declara como posible conflicto de interés ser miembro del Comité Editorial de la RAR.

\section{Bibliografía}

1 Schwartz AN, Goiney RC, Graney DO. Gastric diverticulum simulating an adrenal mass: CT appearance and embryogenesis. AJR Am J Roentgenol 1986;146(03):553-554

2 Jebasingh FK, Naik D, Chandramohan A, Paul MJ. Posterior gastric diverticulum mimicking adrenal adenoma on imaging. BMJ Case Rep 2014;2014:bcr2014207059. Doi: 10.1136/bcr2014-207059

3 Bayraktutan U, Kantarci M, Ogul H, Pirimoglu B, Karaca L, Kizrak Y. A pseudo adrenal lesion: Gastric diverticulum on CT and MR imaging. Eurorad2014Doi: 10.1594/EURORAD/CASE.11716

4 Zuluaga A, Ochoa J, Bustamante S, Gutiérrez C, Zuluaga N. Divertículos y pseudodivertículos del tracto digestivo superior: Hallazgos por tomografía computarizada multidetector (TCMD): Serie de casos. Rev Colomb Radiol 2015;26(01):4139-4144

5 Mahafza WS, Taib AA, Shahait AD, Al Awamleh A. Chronic gastritis in a gastric diverticulum misdiagnosed as a left adrenal mass. Indian J Surg 2015;77(01, Suppl 1):150-152. Doi: 10.1007| s12262-015-1210-2

6 Feng YE, Zhang Z. Gastric diverticulum simulating a left adrenal mass: A case report and review of the literature. Oncol Lett 2015; 10(04):2477-2480 